\title{
Combined heat pump-district heating network energy source
}

\author{
Karolina Kurtz-Orecka ${ }^{1,}$, and Wojciech Tuchowski ${ }^{2}$ \\ ${ }^{1}$ WBiA, West Pomeranian University of Szczecin, al. Piastów 50, 70-311 Szczecin, Poland \\ ${ }^{2}$ WTMiT, West Pomeranian University of Szczecin, al. Piastów 41, 70-001 Szczecin, Poland
}

\begin{abstract}
The article describes the innovative combination of the heat pump's operation with the heating network called as cHPNes. The heat pump's lower heat sources used so far are air, water or ground. Their efficiency is usually incoherent with the energy needs of recipients. In the period of the lowest temperatures of the source, we have the highest demand for heat in the supplied facility. A combination of the water heat pump and the heating network is aimed at increasing the energy efficiency (COP) of the heat source and indirectly increasing the participation of renewable energy in the energy balance of buildings. The essence of the new solution is the use of returning water in the heating network to supply the heat pump evaporator. The working medium temperature of the heating network on the return in the all-year cycle is stable and high, which allows further use of energy of the heating water on the return. These are the two main advantages of network water used as the lower heat source, allowing for stable and efficient operation of the heat pump with COP above 13. This solution is a response to the need to improve the energy efficiency of highly urbanized spaces.
\end{abstract}

\section{Introduction}

The observed climate changes and the depletion of non-renewable energy sources necessitate saving the energy expenditure. Raising the energy efficiency of buildings' exteriors, their installations and sources is reflected in EU stances, including the Energy Performance of Buildings Directive (EPBD). It introduces the necessity to take steps to maximize energy savings (including avoiding energy consumption), primarily in the construction sector, which is estimated to be responsible for the consumption of $40 \%$ of energy generated in the European Union and for the greenhouse gas emissions at $37 \%$ of the total emissions [1]. In Poland, the EPBD directive is reflected in the Construction Law [2] and executive acts to the Act. They specify that new and existing buildings subject to expansion and change of use are to meet the requirements of energy saving. At the same time, the applicable law does not provide for derogation from this basic requirement, which makes it mandatory.

*Corresponding author: karolinakurtz@gmail.com, kurtz@zut.edu.pl 
Energy saving requirements in Poland are defined equally and include the following basic conditions:

- getting the required thermal quality of the building exteriors and its installation technique together with the demonstration of compliance with supplementary requirements, such as the building's non-commencement in the warm season and others, and

- the amount of non-renewable primary energy, expressed as an indicator of the need for non-renewable primary energy, needed to cover the building's utility needs, associated with heating and / or cooling, ventilation, domestic hot water preparation and built-in lighting, must be lower than specified in regulations [1].

The limit values of thermal insulation of partitions and the index of demand for nonrenewable primary energy PE will be tightened in Poland at the end of 2020. This will significantly impede the design process of the building and will force the necessity to apply technical measures to reduce the level of non-renewable primary energy consumption in the facility.

The downtown space is characterized by dense buildings and dense technical infrastructure, which makes it difficult to implement new buildings. This limitation also affects the possibility of shaping the energy efficiency of buildings and achieving compliance with the applicable energy saving conditions. In the case of large scale urban buildings, the problem of achieving high energy performance results from:

- technical limitation of the possibility of applying thermal insulation of external partitions to the thickness of approx. $30 \div 40 \mathrm{~cm}$,

- low sensitivity of energy indicators of large objects to change the thermal insulation of partitions,

- limitation of places of the installation of renewable energy sources on roofs due to their use for the location of technical devices (e.g. ventilation units),

- limitation of roof surfaces in relation to the scale of the building (height and elevation of the buildings), resulting in lack of space for the installation of renewable energy sources of the required size,

- local limitations of the installation of renewable energy sources in flat roofs due to the existence of other technical infrastructure that reduces their efficiency,

- the interaction of buildings, e.g., by shading.

In the energy assessment of the building, the sources of energy used in it are valorised in terms of their sustainability with the environment, through the calculation of the weighing factors of their environmental impact. In the case of non-renewable energy - the non-renewable primary energy input coefficient is above 1, in the case of energy from renewable energy sources in most cases is 0 . This factor has a direct impact on the volume of the demand indicator for non-renewable primary energy PE. New buildings and those subject to major modernization should achieve the nZEB standard, which is achievable, among others through the production of energy for their own needs from renewable energy sources or in the absence of such a possibility - by maximizing the use of energy contained in fuels, i.e. the maximum increase of energy efficiency of devices, including heat sources.

\section{State of the art}

\subsection{District heating networks}

District heating networks are commonly used to transport heat from the place of production to final consumers. The description of technical solutions is well known and generally available in the technical literature. The prototype of currently used heating systems were heating installations from the Greek and Roman times, in which the heat contained in water for heating and bathing was used. The first modern water heating systems were built in the 
18th century in England. The first Polish centralized district heating systems are dated at the turn of the 19th and 20th centuries, were fed with a heating steam, and the heating elements were powered by steam in a direct manner. Mainly for reasons of safety, over time, they started to use steam / water exchangers in which the heating medium was water. Intensive development of heating systems occurred after World War II. In Poland, the first heating rail, connecting the Powiśle Heat and Power Plant with the Palace of Culture and Science, was opened in December in 1953.

\subsection{Heat pumps}

Heat pumps have been widely used in the world for at least two decades. Currently, there are continuous researches in the world to improve the efficiency of heat pumps (COP). The improvement of this parameter dominated all the development directions of these devices, because increasing the COP by several percent translates into significant savings related to the operation of heat pumps and reducing the environmental burden.

The research about the efficiency of a heat pump using seawater was carried out by Haiwen S., Lin D, Xiangli L., and Yinghin Z. [3, 4]. The project concerned a heating system supplying the seaside town of Dalian in China. The heat demand of municipal buildings during the heating period was 5.2 MW. The research was carried out from November 15 to March 15. In the heating season, the lowest outdoor air temperature is $-11^{\circ} \mathrm{C}$, and the average outdoor air temperature is $1.6^{\circ} \mathrm{C}$. The authors derived dependencies determining the amount of energy saved as a result of replacing a conventional heating system with a heat pump. In the analyzed case, the use of a water-based heat pump made it possible to achieve savings of $23.21 \%$ of the total costs incurred for heating in the heating season (compared to a coal-fired boiler room).

In studies published by S. Chao, J. Yiqiang, Y. Yang, D. Shiming [5], the performance of a new heat exchanger (evaporator) of a water heat pump using waste water for powering the lower heat source was presented. The experiment concerned a heat pump using waste water from bathrooms (shower, bathtub, sink, washing machine). Within one month, the influence of impurities formed on the heat exchanger on thermal efficiency of the device was investigated. Data from studies [5] suggest that with increasing biological pollution on the surface of the evaporator during the test period, the daily average evaporating temperature of the refrigerant gradually decreases from $11.4^{\circ} \mathrm{C}$ to $9.4^{\circ} \mathrm{C}$. The daily averaged COP decreased from 3.09 to 2.5. Each time after the cleaning was carried out at the end of the one-month test period, the average evaporating temperature of the refrigerant increased from $9.4^{\circ} \mathrm{C}$ to $11.2^{\circ} \mathrm{C}$, and the average COP increased from 2.5 to 3.04.

Further research is an example of the search for new cooling mixtures for heat pumps. L. Nanxi, L. Shi, H. Lizhong, Z. Mingshan [6] conducted experimental tests on the M1A zeotropic mixture (mass composition of the mixture: $20 \% \mathrm{R} 152 \mathrm{a}$ and $80 \% \mathrm{R} 245 \mathrm{fa}$ ), M1B (mass composition of the mixture: $37 \%$ R152a and 63\% R245fa) and M1C (mass composition of the mixture: $50 \% \mathrm{R} 152 \mathrm{a}$ and $50 \% \mathrm{R} 245 \mathrm{fa}$ ), based on a water-to-water heat pump in the condensing temperature range $70^{\circ} \mathrm{C} \div 90^{\circ} \mathrm{C}$ [6]. The results obtained were compared with refrigerants from the HFC group, R 245fa (GWP $=990)$. The mixture of M1B $(37 \% \mathrm{R} 152 \mathrm{a}$ and $63 \% \mathrm{R} 245 \mathrm{fa})$ is environmentally friendly $(\mathrm{ODP}=0, \mathrm{GWP}=608.8)$ and can be used directly as a replacement for R134a (for the same compressor). At a fixed temperature the cycle has the highest COP (over 3.4) and the best thermodynamic properties of the cycle. The discharge temperature is lower than $110^{\circ} \mathrm{C}$ at $5 \mathrm{~K}$ superheat temperature. The thermal efficiency was much higher than in the case of R245fa. The M1B mixture proved to be a favorable substitute for the water-to-water heat pump working with the R134a mixture (without having to change the compressor) in terms of high efficiency and minimal impact on the environment. In turn, H. Saeng-Li, H. Kim, D. Kang, D. Jung [7] 
carried out research on the mixture R32 / R152a, which was analyzed in the range from $20 \%$ to $50 \%$ of the composition of R32 in the mixture at $10 \%$ intervals, compared to the R22 factor. The tests were carried out on the water heat pump station, while maintaining the same efficiency. The test results indicate [7] that the power consumed by the compressor working with the R32 / R152a mixture is $13.7 \%$ lower than with the compressor operating at R22, and the COP efficiency coefficient obtained for the R32/R152a mixture is $15.8 \%$ higher than for R22. From this point of view, the R32 / R152a mixture is a good substitute for R22. The tests also showed that the temperature of the compression end for the R32/R152a mixture is $15.4^{\circ} \mathrm{C}$ higher than for R22 and the operating costs of the heat pump with the R32 / R152a mixture are reduced by $27 \%$ compared to R 22 .

Research on the heat pump using the heat of water solidification in the lower source was carried out by B. Zakrzewski and W. Tuchowski $[8,9]$. The solution for water heat pumps $[8,9]$ was provided for use in heating and cooling installations, next to which there is a reservoir of water or it can be created, or there is another source of water, including flowing waters. As a result of the tests [10], the COP pump's limit of 4.08 was reached with the difference between the evaporating temperature and the water temperature of $6 \mathrm{~K}$. The team - J. Yu, H. Zhang, S. You also dealt with the use of heat of water solidification in the work of a heat pump. Researchers [11] published a study on the effect of ice formation on the surface of a heat exchanger on the amount of heat captured by means of an indirect heat pump system. A mathematical model describing the heat flow during exchanger operation in conditions of non icing and icing conditions was presented. The model assumes the operation of the device in conditions of low outside temperatures. The heat is supplied to the heat pump via an intermediate system, which consists of a glycol solution pump, a measuring system and a CHE (Casted Heat Exchange). The heat exchanger in the form of rolled polyethylene pipes is placed in seawater. Inside the exchanger, a $10 \%$ solution of ethylene glycol flows. The device was compared in conditions of low external temperatures which were favorable for icing the surface of the heat exchanger with an icecold exchanger operating in the same conditions. The authors [11] have proved that the ice created on the surface of the exchanger significantly increases the thermal resistance and thus reduces the amount of heat absorbed. Unfortunately, the authors did not present the results of the COP energy efficiency tests of the device and its variability during icing of the heat exchanger. They also did not specify at what thickness of the ice layer thermal efficiency tests were carried out.

All commonly used heat sources supplying heat pumps are characterized by incoherentness. In the period of the lowest temperatures of the source, the highest demand for heat occurs in the supplied facility. In addition, in many cases there are significant fluctuations in the source temperature, which hinders correct control of the device operation and causes difficulties in reliably estimating its energy efficiency ratio. Nevertheless, heat pumps, compared to other heating devices, have the lowest operating costs. For example, for the design temperature of the outside air in the winter period, for example $-16^{\circ} \mathrm{C}$, the air heat pumps show the actual $\mathrm{COP} \approx 1.5$ energy efficiency ratio. Such a low result depends on several components, but undoubtedly two of them are dominant, i.e. low air temperature and high relative humidity of cold air. If the air temperature drops below $2{ }^{\circ} \mathrm{C}$, the air pump starts to condense and freeze moisture on the heat pump's evaporator. A layer of frost forms, which simultaneously reduces heat transfer to the exchanger, as well as increases the resistance of air flowing through the exchanger. This phenomenon enforces the use of socalled defrosting, which significantly worsens the value of COP (due to the additional energy consumption of the device for the needs of defrosting) and enforces periodic breaks in the work, which are intended for cleaning the exchanger from frost (defrosting). Another disadvantage of these devices is also the noise generated by fans in external heat 
exchangers (evaporators). The greater the power of the device, the greater the noise that sometimes exceeds $70 \mathrm{~dB}$ in the surrounding area.

Ground heat pumps are devices in which direct evaporation of the refrigerant is rarely used. They work more often in indirect systems, in which the brine or glycol, circulating in the intermediate system, is additionally involved in heat transfer. Ground heat pumps generally have a higher COP energy efficiency coefficient (under the same operating conditions), however, an additional intermediate circuit requires the use of a brine or glycol pump, which in turn reduces the coefficient. These devices can work with indirect heat exchangers located in vertical or horizontal form. In a highly urbanized zone, the solution with horizontal exchangers is unparalleled (due to the need to have large ground areas), while the solution with vertical exchangers encounters difficulty in implementation due to the dense network of channels and other underground infrastructure.

Water-based heat pumps have the highest average energy efficiency ratio of all heat pumps. Water as a source of heat, is characterized by the highest specific heat. The potential of water as a source of heat depends on its source. Unfortunately, as in the case of other solutions, in the period of the highest heat demand for heating the object, the water source usually has the lowest temperature. In addition, in the case of using surface water, there is a risk of freezing the water surface and therefore - interruption of heat pump operation. There are already patented solutions that allow for continuous operation of these devices even when the tank surface is frozen, e.g. a lake. It is also possible to draw geothermal water to power the heat pump evaporator. Geothermal water has a high temperature potential, however, as a rule, it does not exceed $30^{\circ} \mathrm{C}$. There are also known solutions for water heat pumps that use municipal sewage as the lower heat source. In this case, an intermediate system is necessary due to the corrosive effect of sewage and a special construction of heat exchangers that do not increase flow resistance and do not require frequent servicing. In a heavily urbanized area, water heat pumps are more and more often used as a source of heat, using flowing waters - eg. a local river. Such systems are usually of high power (often exceeding $500 \mathrm{~kW}$ of heating power) and operate using an intermediate circuit. The energy efficiency ratio of such systems varies, depending on the temperature of river water, and in practice is rarely higher than $\mathrm{COP}=4$.

\subsection{Combined systems}

There are also heating systems that in their construction include a heating network and a heat pump. However, they are not combined into one system that would act as an integrated heat delivery system. As independent, they form the so-called bivalent heat source.

\section{Integrating and linking heat pump to heat network}

In order to improve the energy efficiency of buildings, it was proposed to improve the energy efficiency of the heat source. The water-to-water heat pump has been associated with the heating network to form one integrated heat supply system [10] - combined heat pump - network energy source (cHPNes). In this system, the heat pump operates depending on the heating network. The system includes a heating network and a water-to-water heat pump, whereby the working medium of the heating network is the heat pump's lower source. The device will operate in a monovalent system. 


\section{$3.1 \mathrm{cHPNes}$ system with a substation}

The operation of the cHPNes system with a heat substation covers the operation of the system in which the heat pump cooperates with the district heating network through a heat exchanger. The water drawn on the return from the heating network is directed to the indirect heat exchanger - the substation, and then via the intermediate liquid to the heat pump evaporator. The network water after heat transfer to the refrigerant in the heat pump system is directed to the return of the heating network (Fig. 1). Figure 1 indicates: 1 - return and 1' - supply of the heating network, 2 - heat pump, 3 - heating connection, 4 - substation, 5 - supply pipeline, 6 - return pipeline, 7 - indirect layout of the heat pump, 8 - shut-off armature, 9 - storage or heat-cutting system.

In this system it is possible to regulate the mass flow of flowing water from the district heating network through an intermediate heat exchanger depending on the heat demand and the possibility of mass flow regulation in the intermediate circuit.

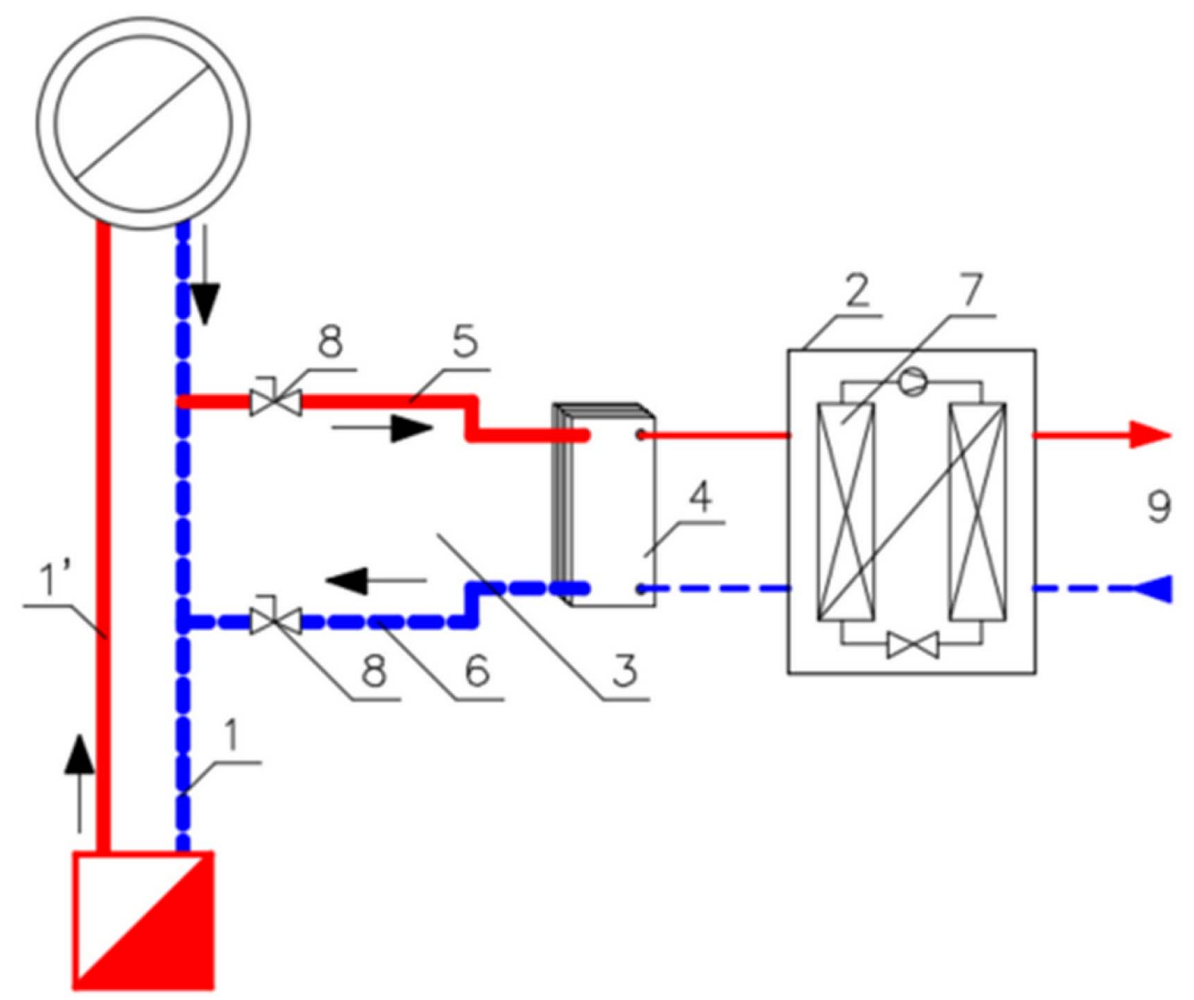

Fig. 1. The cHPNes system with a substation. Description of symbols in the text.

\section{$3.2 \mathrm{cHPNes}$ system without a substation}

The cHPNes system of the co-operating heat pump and district heating network, excluding the substation, predicts that the return water from the heating network is pumped directly through the heat pump evaporator. In the evaporator, the heat is withdrawn from the network water and by thermodynamic changes of the refrigerant, transferring it to the water washing the condenser (heating water) - Fig. 2. In this system, it is possible to regulate the mass flow of water flowing from the heating network through the evaporator depending on the heat demand. Network water after the heat transfer to the refrigerant in the heat pump 
system is directed to the return of the heating network. It is possible to draw water from the heating network to the heat pump's evaporator or to mix two streams of water from the heating network and direct the stream to the heat pump's evaporator. The network water temperature in the supply is approx. 75 to $120^{\circ} \mathrm{C}$.

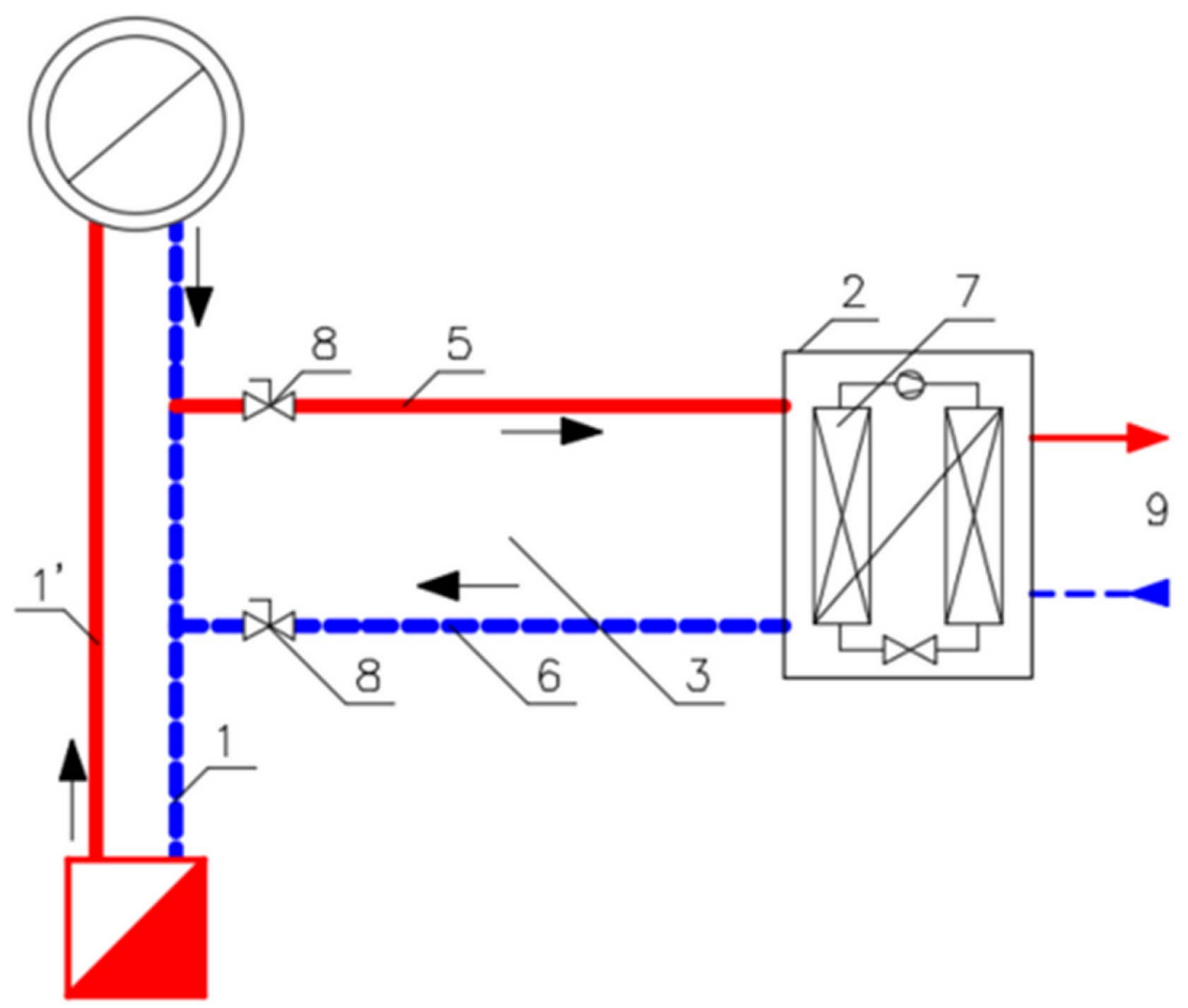

Fig. 2. The cHPNes system without a substation. Symbol description the same like in Fig.1.

\section{Benefits of the cHPNes}

The combination of a water heat pump with a district heating network in a monovalent system (cHPNes) increases the energy efficiency (COP) of a heat source and indirectly increases the share of wasted energy in the energy balance of existing and new buildings. The essence of the new solution [10] is the use of water at the return of the heating network to supply the heat pump evaporator. The temperature of the water in the heating network on the return fluctuates from $45^{\circ} \mathrm{C}$ to $60^{\circ} \mathrm{C}$. The solution allows getting advantages from both within the source itself as well as the power supply.

The solution of the monovalent operation of the heat pump system and district heating network (cHPNes) is part of strongly urbanized areas with the existing heating network, where for various reasons it is not possible to use renewable energy sources. The cHPNes system has three main advantages, which determine the achievement of a high energy efficiency ratio (COP): high temperature of the lower heat source - heating network, large volume of water flow in the heating network and temperature stability of the medium.

The temperature of water in the return pipeline of the heating network in winter does not fall below $45^{\circ} \mathrm{C}$, which at a heating water temperature after the condenser at $60^{\circ} \mathrm{C}$ guarantees the achievement of COP above 13. In addition, the large mass flow of water 
from the heating network guarantees the achievement of high energy efficiency coefficients. A relatively constant, high temperature of the lower heat source, which is the heating water, allows to achieve a constant high COP value.

Additional benefits of the solution include:

- improving the heat supply conditions of large buildings, including cubature ones, in urban areas that provide the possibility of connection to the heating network, complying with the applicable regulations in the field of energy saving,

- optimization of the object's implementation costs by avoiding the costs of using inefficient sources of heat in urban space,

- the use of heat from the heating network's return line helps reduce the temperature of the medium in the return pipeline, which is desirable in the optimization of the heating network operation (the largest temperature difference between the supply and return of the network),

- the energy supplier, as an obliged entity, can save the final energy consumption of the end user, which he is obliged to under energy law.

\section{References}

1. Directive 2010/31/EU of the European Parliament and of the Council of 19 May 2010 on the energy performance of buildings, Official Journal of the European Union, L 153/13 (2010)

2. Act of 7 July 1994 on construction law, Official Journal of Poland, Dz.U. 12, 317, 352 (2018)

3. S. Haiwen, D. Lin, L. Xiangli, Z. Yinghin, Energy and Build., 42, 889-895 (2010)

4. S. Haiwen, D. Lin, L. Xiangli, Z. Yinghin, Energy and Build., 42, 2424-2430 (2010)

5. S. Chao, J. Yiqiang, Y. Yang, D. Shiming, Appl. Energy 95, 202-209 (2012)

6. L. Nanxi, L. Shi, H. Lizhong, Z. Mingshan, Appl. Energy 80, 435-447 (2005)

7. H. Saeng-Li, H. Kim, D. Kang, D. Jung, Energy 40, 100-106 (2012)

8. B. Zakrzewski, Wodna pompa ciepła i sposób optymalizacji pracy wodnej pompy ciepła, (PL 209839 B1,2009)

9. B. Zakrzewski, W. Tuchowski, Wodna pompa ciepła i sposób optymalizacji pracy wodnej pompy ciepta, (PL 219940 B1, 2013)

10. W. Tuchowski, Badania eksperymentalne efektywności pompy ciepła wykorzystujacej utajone ciepło zamarzania wody. (Autoreferat rozprawy doktorskiej. ZUT w Szczecinie, WTMiT, Szczecin,2015)

11. J. Yu, H. Zhang, S. You, Renewable Energy 41, 39-43 (2012)

12. W. Lloy, A Hospital on the Lake =, https://www.csemag.com/industry-news/codes-andstandards-updates/single-article/a-hospital-on-the-lake/ fd8d15cfd2eb314a7cfe81b62674f6cd.html (2001)

13. 2002 ASHRAE Technology Awards, L. Joyce, Cornell University Department of Utilities and Energy Management in Ithaca, New York, USA, https://www.buildinggreen.com/newsbrief/2002-ashrae-technology-awards (2002)

14. K. Kurtz-Orecka, K. Koczergo, W. Tuchowski, Sposób podnoszenia efektywności energetycznej pompy ciepla z wykorzystaniem sieci ciepłowniczej - The method of increasing the energy efficiency of a heat pump and the system of heat and cold supply, (Polish Patent Application WIPO ST 10/C PL425267, 2018) 